\title{
Penerapan Algoritma Surf Pendeteksi Objek Pada Augmented Reality Berbasis Android
}

\author{
Amir Alkodri ${ }^{1}$, Harrizki $^{2}$, Suharno $^{3}$ \\ ${ }^{1,2}$ STMIK Atma Luhur, Jl. Jend Sudirman, Selindung, Pangkalpinang. Kep. Bangka Belitung \\ ${ }^{3}$ Program Studi Teknik Informatika, STMIK Atma Luhur, Bangka Belitung \\ e-mail: *11arie_a3@atmaluhur.ac.id, ${ }^{2}$ harrizkiariep@atmaluhur.ac.id, ${ }^{3}$ suharno@atmaluhur.ac.id
}

\begin{abstract}
Abstrak
Untuk penerapan konsep yang efektif dan efisien dalam pembelajaran menggunakan teknologi augmented reality yang interaktif. Pembelajaran multimedia merupakan bentuk pembelajaran secara interaktif. Pembelajaran dapat dilakukan dikelas maupun dalam bentuk tugas dirumah. Dampak dari pembelajaran interaktif ini sangat mempengaruhi kualitas pemahaman bagi pengguna. Berdasarkan pengujian dari teknologi augmented reality, penelitian, analisis dan analisis desain antarmuka interaktif, proses dan prinsip dilakukan melalui interaksi manusia dan komputer serta pengalaman pengguna. Metode desain antarmuka menggunakan metode Object Oriented Programming dan algoritma Speeded Up Robust Features. Hasil penelitian menunjukkan bahwa augmented reality interaktif dapat memberikan metode baru dalam proses pembelajaran dan memperbarui konten pembelajaran di kelas. Singkatnya, metode ini meningkatkan partisipasi dan antusiasme siswa, dan meningkatkan efektivitas pembelajaran.
\end{abstract}

Kata kunci: Augmented Reality, Interaktif, Speeded Up Robust Features

\begin{abstract}
For the application of effective and efficient concepts in learning using interactive augmented reality technology. Multimedia learning is a form of interactive learning. Learning can be done in class or in the form of assignments at home. The impact of interactive learning greatly affects the quality of understanding for users. Based on testing from augmented reality technology, research, analysis and analysis of interactive interface design, processes and principles are carried out through human and computer interaction as well as user experience. The interface design method uses the Object-Oriented Programming method and the Speeded Up Robust Features algorithm. The results showed that interactive augmented reality can provide new methods in the learning process and update learning content in the classroom. In short, this method increases student participation and enthusiasm, and increases learning effectiveness.
\end{abstract}

Keywords: Augmented Reality, Interactive, Speeded Up Robust Features

\section{PENDAHULUAN}

Pesatnya perkembangan teknologi komputer, teknologi interaksi antara manusia dan komputer telah diperbarui secara interaktif. Interaksi manusia terhadap komputer mengacu pada proses pertukaran informasi antara seseorang dan komputer menggunakan bahasa dialog tertentu dan berinteraksi satu sama lain untuk menyelesaikan tugas tertentu. Dalam proses desain interaksi saat ini, interaksi manusia terhadap komputer telah berjalan dan diteliti di dalam maupun di luar industri [1]. Augmented Reality (disebut sebagai AR) dapat dianggap sebagai salah satu dari Virtual Reality (VR). Augmented reality adalah penggunaan komputer untuk menciptakan lingkungan virtual dengan perasaan visi, pendengaran, kekuatan, sentuhan, dan 
gerakan yang realistis. Dengan melalui beberapa perangkat sensor dalam lingkungan virtual untuk mencapai interaksi alami langsung antara pengguna dan lingkungan. Ini dapat mensimulasikan lingkungan antarmuka interaksi manusia dan komputer yang canggih menggunakan komputer berdasarkan interaksi dan konsep. Pengguna tidak bisa hanya mengalami perasaan mendalam yang dialami dalam dunia fisik objektif melalui sistem realitas virtual, tetapi juga dapat menembus ruang, waktu, dan batasan objektif lainnya, dan merasakan pengalaman yang tidak dapat dialami di dunia nyata. Augmented reality menyediakan metode penggabungan dunia virtual dengan dunia nyata. Itu adalah salah satu mode pengembangan penting dari era antarmuka interaktif 3D.

Dalam penelitian ini, selama era interaksi manusia dan komputer itulah penulis berusaha menggunakan teknologi augmented reality sebagai titik awal untuk menganalisis persyaratan antarmuka interaktif berdasarkan augmented reality [2]. Dari aspek interaksi manusia dan komputer, pengalaman pengguna, komunikasi visual, desain emosional, dan aspek lainnya, desain, konten, aliran, dan prinsip-prinsip antarmuka interaktif dipelajari dan dianalisis untuk merangkum metode desain antarmuka interaktif berdasarkan augmented reality [3]. Dengan menggunakan teknologi augmented reality di bidang pendidikan mahasiswa sebagai latar belakang, metode desain antarmuka interaktif dipraktikkan dan hasil penelitiannya dilakukan pengujian. Dalam desain antarmuka yang bertujuan untuk mengeksplorasi dan memulai, sehingga pengguna dapat belajar dari pengembangan umum, dan terus memperdalam desain antarmuka di komputer pada bidang pendidikan, bidang pemerintahan, bidang keilmuan, dan perusahan-perusahan lainnya [4]. Dalam penelitian ini dilakukan pembuatan aplikasi augmented reality yang interaktif 3D pembelajaran berbasis android Penerapan Algoritma SURF Pendeteksi Objek pada Augmented Reality.

\section{METODE PENELITIAN}

\subsection{Model Waterfall}

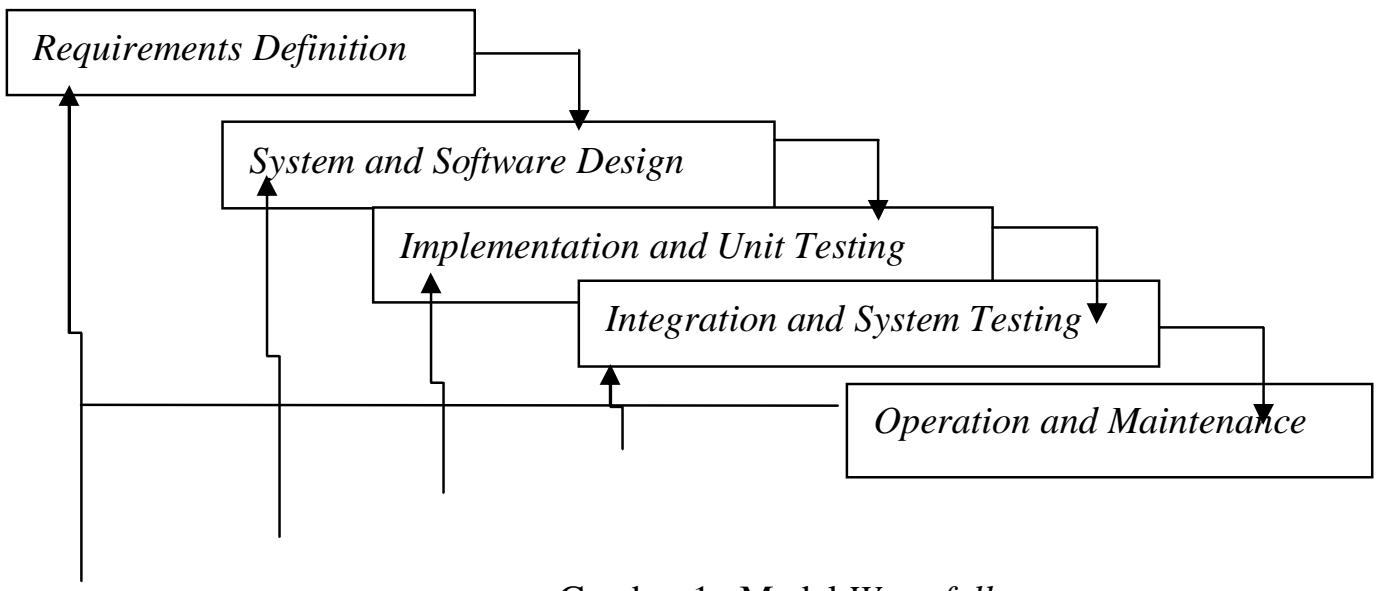

\section{Requirements Definition}

Gambar 1. Model Waterfall

Pada tahap pertama model Waterfall ini proses pencarian kebutuhan (Requirements Definition) bertujuan untuk mengetahui sifat dari program yang akan dibuat. Penulis mengumpulkan data bagaimana proses terjadinya gerhana matahari dan bulan, perputaran objek, bayangan, cahaya dan lain-lain. Serta fungsi yang dibutuhkan seperti User Interface, output suara yang akan menjelaskan proses bagaimana kejadian tersebut bisa terjadi dan lain-lain. Software pengolah objek 3D, bahasa pemrograman JavaScript, C\# akan dibutuhkan pada pembuatan aplikasi m-learning ini. 


\section{System and Software Design}

Tahap kedua adalah pembuatan design sistem sebelum proses coding mulai, tahap ini dapat dimulai dari membuat objek yang akan ditampilkan dalam bentuk tiga dimensi, persiapan output suara, user interface, fitur-fitur yang ada ini akan membantu user dalam menggunakan aplikasi.

3. Implementation and Unit Testing

Pada tahap ketiga waterfall ini design harus diubah bentuknya menjadi bentuk yang dapat dimengerti oleh mesin, yaitu ke dalam bahasa pemrograman melalui proses coding. Tahap ini merupakan implementasi dari tahap design.

4. Integration and System Testing

Tahap ke empat adalah proses uji coba aplikasi dari kebutuhan setiap tahap sebelumnya untuk memastikan tidak ada lagi error atau bug dalam aplikasi yang dibuat.

5. Operation and Maintenance

Perbaikan dibutuhkan bila aplikasi mengalami error yang tidak ditemukan sebelumnya serta pengembangan aplikasi seperti penambahan fitur baru.

\subsection{Metode Object Oriented Programming}

Pemrograman berorientasi objek digunakan dalam penulisan kali ini karena memiliki banyak keunggulan dalam penanganan tugas yang kompleks.Pemrograman menggunakan bahasa berorientasi objek mengikuti konsep-konsep berorientasi objek terutama dalam hal fleksibilitas, kegunaan, dan kemudahan pemeliharaan. Metode ini akan mengorganisasikan perangkat lunak sebagai kumpulan objek yang berisi data dan operasi yang dilakukan terhadapnya.

\subsection{Tools Pengembangan Sistem}

Pada penulisan kali ini alat atau tools yang digunakan untuk mengembangkan sistem adalah tools UML (Unified Modeling Language), yang terdiri dari:

1. Use Case Diagram

Berfungsi untuk menggambarkan hubungan antara user (pengguna) dengan sistem aplikasi. Melalui diagram usecase dapat diketahui fungsi apa saja yang terdapat pada sistem aplikasi augmented reality ini.

2. Activity Diagram

Activity diagram menampilkan aktifitas yang terjadi pada usecase, bukan apa yang dilakukan aktor, namun aktivitas yang dapat dilakukan oleh sistem aplikasi.

\section{Class Diagram}

Class Diagram merupakan inti dari pengembangan dan design berorientasi objek, serta bagaimana caranya agar pengguna dengan sistem aplikasi bisa saling berhubungan untuk mendapatkan hasil yang diinginkan.

4. Sequence Diagram

Sequence Diagram menggambarkan interaksi antar objek berupa pengiriman data antar objek dalam urutan waktu. Interaksi antar objek tersebut dapat berupa pesan (messages), pengguna (user), dan tampilan (display).

\subsection{Algoritma Speeded Up Robust Features}

Algoritma ini penulis gunakan karena algoritma SURF memiliki kemampuan deteksi citra yang cepat dan dapat mendeskripsikan citra yang terdeteksi secara unik. Memiliki ketahanan terhadap transformasi citra seperti perubahan rotasi, skala, pencahayaan, gangguan noise dengan intensitas tertentu, dan perubahan sudut pandang. Algoritma SURF merupakan pengembangan dari algoritma SIFT dimana SURF memanfaatkan kecepatan komputasi tapis kotak dengan menggunakan citra integral. Berikut adalah tahap-tahap bagaimana algoritma SURF berjalan [5]: 
1. Konversi citra RGB ke Grayscale

Tahap awal dari algoritma SURF adalah mempersiapkan citra masukan dengan format grayscale 32-bit. Citra integral $I$ adalah representasi tengah (intermediate) untuk citra dan terdiri dari jumlah nilai keabuan dari citra $N$ dengan tinggi $=y$ dan lebar $=x$. Perumusannya pada gambar 2.

$$
I(x, y)=\sum_{x=0}^{x} \sum_{y=0}^{y} N\left(x^{\prime}, y^{\prime}\right)
$$

\section{Mendeteksi Titik Fitur}

\section{Gambar 2. Konversi Citra RGB ke Grayscale [6]}

Dari fitur Haar-like maka hanya dipilih fitur gelembung (blob-like feature) untuk mendeteksi titik-titik fitur. Adapun pertimbangan pemilihan fitur gelembung adalah untuk mengurangi jumlah fitur yang terdeteksi dan lebih mempercepat waktu komputasi. Pada tahap kedua ini terbagi lagi menjadi beberapa langkah yang terdiri dari [6]:

a. Pembentukan Piramid Citra

Untuk membentuk piramid citra digunakan box filter sebagai aproksimasi dari turunan parsial kedua dari Gaussianpada gambar 3.
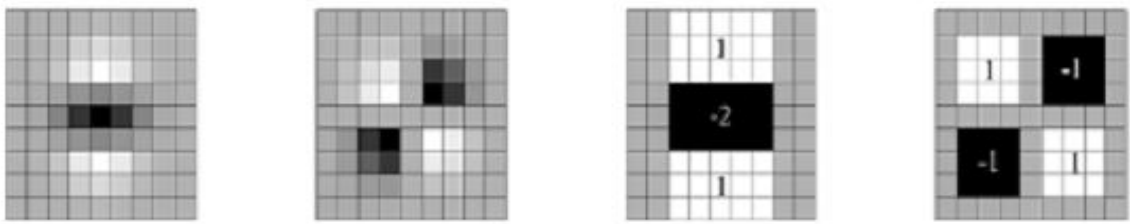

Gambar 3. Turunan Parsial Kedua dari Gaussian

b. Mencari ekstrema dari determinan matriks Hessian

Citra dengan skala yang lebih kecil dibentuk dari konvolusi citra $I$ dengan up-scalling box filter sebelumnya. Pada tahap pendeteksian fitur digunakan matriks Hessian karena memiliki performa yang baik dalam kecepatan waktu komputasi dan akurasi. Matriks Hessian di titik $x=(x, y)$ dari citra $I$ dengan skala $\sigma$ pada gambar 4 .

$$
\mathrm{D}=(\mathrm{A}+\mathrm{B}+\mathrm{C}+\mathrm{D})-(\mathrm{A}+\mathrm{B})-(\mathrm{A}+\mathrm{C})+\mathrm{A}
$$

Gambar 4. Matriks Hessian

Agar fitur yang terdeteksi tahan terhadap penskalaan maka dicari ekstrema dari matriks Hessian dengan perumusan pada gambar 5 .

$$
\operatorname{det}\left(H_{\text {approx }}=D_{(x x)} D_{y y}-\left(0,9 D_{x y}\right)^{2}\right.
$$

Gambar 5. Perumusan Ekstrema Matriks Hessian

Kemudian ekstrema dari determinan matriks Hessian di interpolasikan pada skala ruang dengan metode yang diajukan oleh Brown. Metode ini akan diterapkan pada setiap calon fitur untuk mencari lokasi extrema setelah di interpolasi. 3 Dquadratic menggunakan ekspansi Taylor terhadap fungsi scale-space, $D(x, y, \sigma)$, yang digeser sedemikian rupa sehingga titik aslinya digunakan sebagai titik uji pada gambar 6 .

$$
D(x)=D+\frac{\partial D^{T}}{\partial x} x+\frac{1}{2} x^{T} \frac{\partial^{2} D}{d x^{2}} x
$$

Gambar 6. Perumusan Titik Uji

Dimana $D$ dan turunanya dihitung pada titik uji dan $x=(x, y, \sigma)^{T}$ adalah simpangan dari titik uji. Sedangkan lokasi ekstremum dapat dihitung, pada gambar 7.

$$
\hat{x}=\frac{\partial^{2} D^{-1}}{\partial x^{2}} \times \frac{\partial D}{\partial x}
$$

Gambar 7. Perumusan Lokasi Ekstremum 
SURF beroprasi dengan cara mengurangi ruang pencarian dari kemungkinan titik penting. Pada gambar 8 memperlihatkan proses non-max suppression untuk mendapatkan keypoints.

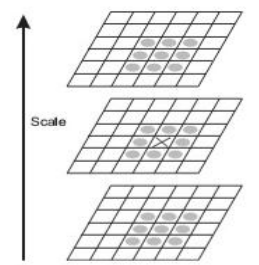

Gambar 8. Non-max Suppression [7]

Agar tahan terhadap rotasi, maka setiap keypoints yang terdeteksi akan diberikan orientasi. Pertama akan dihitung respon Haar-wavelet terhadap sumbu $-x$ dan sumbu $-y$ dengan titik-titik di lingkungan tetangganya seperti pada gambar 9 .

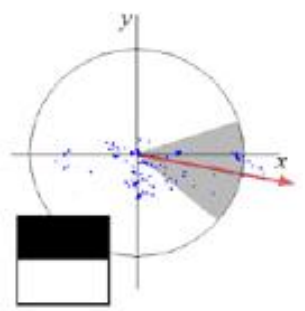

Gambar 9. Pemberian Orientasi [8]

Proses awal yang akan dilakukan adalah mencocokan orientasi yang dihasilkan berdasarkan informasi dari daerah yang berbentuk lingkaran disekitar pixel. Kemudian membuat daerah berbentuk kotak pada orientasi yang terpilih dan mengekstrak deskriptor SURF dari daerah tersebut, selanjutnya proses matching fitur antara dua gambar dilakukan.

3. Inisiasi

Langkah pertama inisiasi adalah aplikasi akan melakukan pengaturan pada tampilan device atau smartphone, seperti pengaturan layout, penempatan background, penempatan button dan lain-lain. Setelah itu sistem akan memulai proses pembuatan deskriptor terhadap marker yang telah penulis siapkan dalam database aplikasi EclipseAR. Saat proses inisialisasi berjalan, sistem akan mengolah marker pada database satu kali saja pada saat aplikasi sedang di install.

Dalam proses pembuatan deskriptor pertama citra atau gambar yang didapat akan diproses oleh algoritma SURF untuk mencari keypoints dari citra tersebut. Setelah didapatkan, proses selanjutnya adalah mencari deskriptor dari citra tersebut, deskriptor inilah yang dibutuhkan untuk proses pencocokan marker pada database dengan citra yang di tracking oleh ARCamera [9].

\section{Tracking Marker}

Pendeteksian gambar dan perhitungan posisi gambar dilakukan dengan menggunakan algoritma SURF, dimana aplikasi akan menjalankan ARCamera dari smartphone untuk mengambil gambar marker. Informasi posisi yang didapatkan nantinya akan digunakan untuk menempatkan objek atau model pada marker. Ada 4 tahapan dalam proses tracking marker, yaitu [10]:

a. Tracking marker dari kamera smartphone.

b. Ekstraksi keypoints menjadi deskriptor menggunakan SURF.

c. Corner detection.

d. Pencocokan pola.

Proses pembentukan deskriptor dilakukan dengan membuat kotak persegi disekitar keypoint. Sehingga akan dihasilkan area yang memiliki bentuk segi empat dan pola-pola citra yang sudah ditandai. Pola tersebut dibentuk untuk menghasilkan deskriptor yang siap diolah untuk pencocokan citra. 
Deskriptor tersebut mengandung informasi terkait koordinat keypoint dan jumlah keypoint yang dihasilkan dari hasil komputasi. Tahap terakhir adalah pencocokan pola setelah area persegi dan pola gambar ditandai, citra yang berada di dalam persegi dianalisa dan dibandingkan polanya dengan sekumpulan pola yang telah ditentukan sebelumnya.

\section{Render Objek}

Setelah mendapatkan hasil dari proses perhitungan menggunakan algoritma SURF, maka langkah selanjutnya adalah menampilkan hasil augmented reality berupa objek tiga dimensi [11]. Citra yang ditangkap oleh ARCamera dikatakan cocok ketika variabel FoundState yang diproses saat tracking marker memiliki status true. Setelah diketahui bahwa status tracking marker tersebut adalah true maka informasi mengenai objek tersebut akan ditampilkan berdasarkan variabel index Proses [12].

\section{HASIL DAN PEMBAHASAN}

\subsection{Tampilan Layar}

1. Splash Screen

Splash screen adalah tampilan awal pada aplikasi yang menampilkan logo Unity kemudian disusul dengan tampilan main menu dan lain-lain seperti pada Gambar 10.

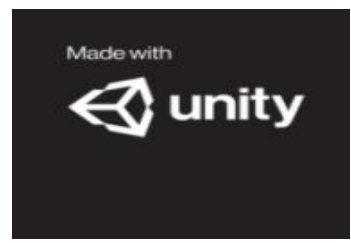

\section{Main Menu}

Gambar 10. Tampilan Layar Splash Screen

Fungsi button pertama dan kedua adalah untuk beralih ke scene gerhana matahari atau scene gerhana bulan kemudian menampilkan objek tiga dimensi suara dan animasi jika marker yang digunakan cocok. Quit button berfungsi untuk menutup aplikasi.Adapun Main Menu bisa dilihat pada Gambar 3.2.

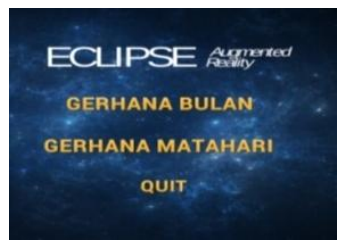

3. Gerhana Matahari

Gambar 11.Tampilan layar Main Menu

Tampilan utama pada layar adalah area kamera AR yang nantinya digunakan untuk tracking marker menggunakan seluruh layar.Scene gerhana matahari menampilkan animasi tiga dimensi bumi, bulan, matahari, suara dan bagaimana proses terjadinya gerhana matahari dari awal sampai selesai. Pada tampilan ini terdapat dua button yaitu play dan menu, play button berfungsi untuk memulai animasi dan memunculkan suara sedangkan menu button berfungsi untuk kembali ke mеnu utama.Adapun gambar gerhana matahari bisa dilihat pada Gambar 3.3. 


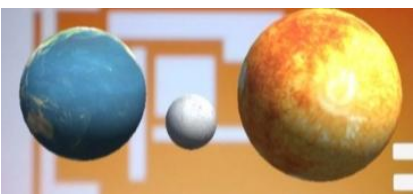

4. Gerhana Bulan

Gambar 12. Tampilan Layar Gerhana Matahari

Scene gerhana bulan memiliki pola yang sama dengan scene gerhana matahari, tiga objek 3D dan dua button. Yang membedakan kedua scene ini adalah letak objek tiga dimensi dan output suara yang dihasilkan.Untuk Gerhana Bulan bisa dilihat pada Gambar 13.

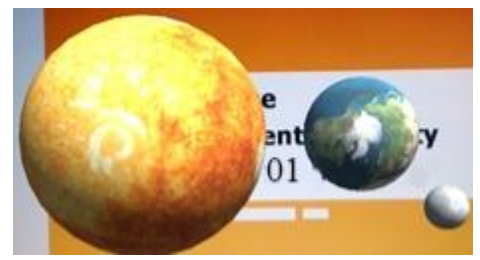

Gambar 13.Tampilan Layar Gerhana Bulan

\subsection{Algoritma SURF}

\section{Script Algoritma SURF}

Berikut adalah script algoritma Speeded Up Robust Features yang penulis gunakan pada pembuatan aplikasi mobile learning gerhana. Script ini terletak pada Vuforia dan berfungsi sebagai inisiasi awal ARCamera, menangkap pola marker, menentukan status tracking, eksekusi fungsi tracking ditemukan atau tracking tidak ditemukan.

a. Inisiasi Awal

Script dibawah berfungsi sebagai inisiasi awal saat tracking dijalankan kemudian mengambil pola marker yang ada pada sistem.Untuk Script algoritma SURF dilihat pada gambar 3.5.

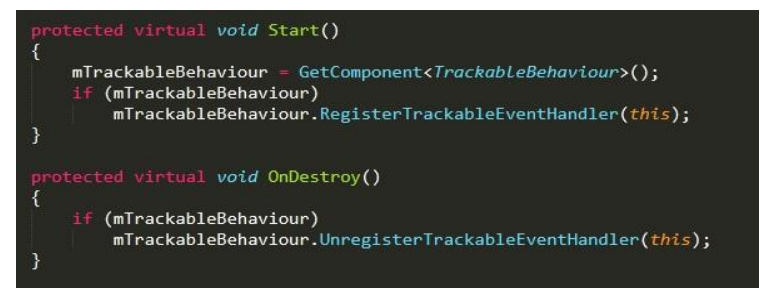

b. Status Tracking

Gambar 14. Script Inisiasi Awal

Script ini adalah langkah selanjutnya dari script inisiasi, setelah selesai menjalankan perintah pertama maka langkah selanjutnya adalah menentukan status tracking. Jika sistem menemukan marker yang berada pada database dan marker tersebut cocok maka fungsi On Tracking Foundakan dijalankan, sebaliknya jika marker tidak ditemukan atau tidak cocok dengan database maka fungsi On Tracking Lost akan digunakan oleh sistem.

Untuk status tracking bisa dilihat pada Gambar 15. 


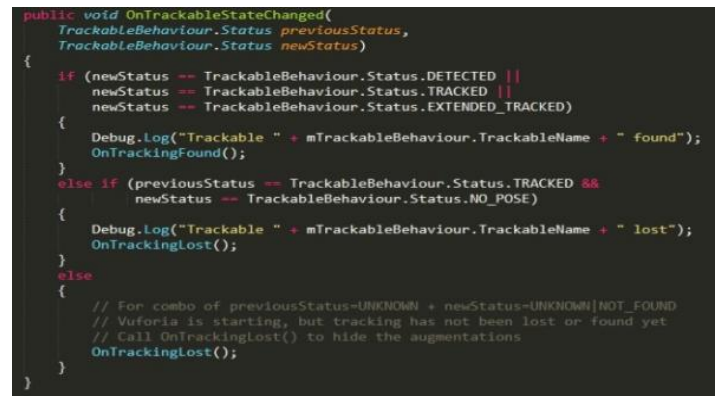

Gambar 15. Status Tracking

c. On Tracking Found

Setelah proses status tracking selesai dan marker ditemukan maka sistem akan memberi nilai true pada tiga komponen yaitu rendered, collider dan canvas. Langkah ini bertujuan untuk memunculkan ketiga objek tersebut diatas marker dalam bentuk objek dua atau tiga dimensi pada saat ARCamera dijalankan dan marker ditemukan. Sedangkan untuk on tracking found bisa dilihat pada gambar 16.

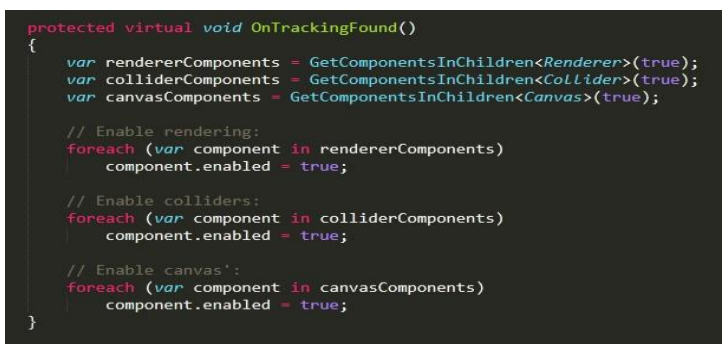

Gambar 16. Script On Tracking Found

d. On Tracking Lost

Kebalikan dari fungsi On Tracking Found, fungsi script ini adalah jika pada saat status tracking sistem tidak menemukan marker yang cocok pada database atau marker belum ditempatkan dengan benar maka sistem akan menjalankan perintah ini. Dengan cara memberi nilai false pada ketiga komponen, fungsi tersebut membuat tampilan ARCamera tidak menampilkan objek apapun saat dijalankan. Untuk tampilan on tracking lost bisa dilihat pada Gambar 17.

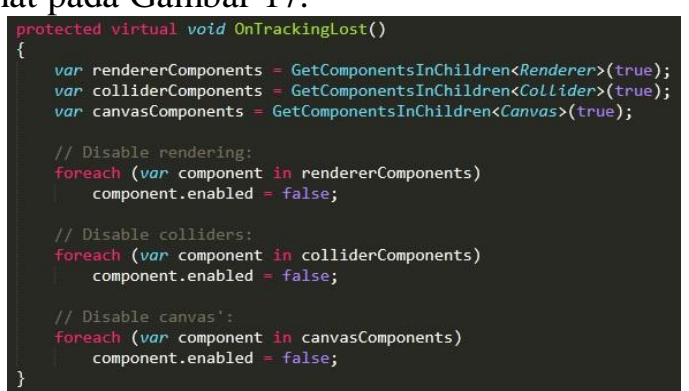

Gambar 17. Script On Tracking Lost

\section{KESIMPULAN}

Dari rumusan masalah yang telah ditentukan dalam penerapan algoritma SURF pendeteksi objek pada augmented reality berbasis android, maka dapat disimpulkan bahwa dalam membuat lima objek tiga dimensi menggunakan aplikasi Blender 3D sebagai penentuan implementasi, dalam proses gunakan pada pembuatan aplikasi mobile learning gerhana. Script 
ini terletak pada Vuforia dan berfungsi sebagai inisiasi awal ARCamera. Pengujian kinerja algoritma SURF dalam kemampuan mendeteksi objek Grayscale berdasarkan cahaya lebih optimal, tingkat intensitas cahaya sangat mempengaruhi terhadap pendeteksi objek 3 dimensi oleh kamera.

Semakin tinggi tingkat intensitas cahaya, maka semakin banyak pula interest point yang tampil pada objek.

\section{SARAN}

Setelah mengevaluasi keseluruhan, beberapa saran yang dapat penulis berikan untuk pengembangan aplikasi ini kedepannya adalah sebagai berikut:

1. Jumlah objek tiga dimensi dalam aplikasi masih tergolong sedikit, diharapkan kedepannya agar objek tiga dimensi lainnya dapat ditambahkan agar informasi yang disampaikan jadi lebih banyak.

2. Penambahan fitur untuk menyalakan lampu flash pada kamera sehingga marker dapat terdeteksi oleh ARCamera dan mengembangkan platform agar dapat berjalan pada sistem operasi lainnya.

\section{DAFTAR PUSTAKA}

[1] Gallayanee Yaoyuneyong, Jamye K. Foster \& Leisa R. Flynn 2014, Factors Impacting The Efficacy of Augmented Reality Virtual Dressing Room Technology As a Tool for Online Visual Merchandising, Journal of Global Fashion Marketing, 5:4, 283-296, DOI: $10.1080 / 20932685.2014 .926129$

[2] Nielsen, J.and Molich, R. "Heuristic Evaluation of User Interfaces", In Proceedings of ACM CHI'90 Conference on Human in Computing Systems, pp.25-62.

[3] Chang, K. E., Chang, C. T., Hou, H. T., Sung, Y. T., Chao, H. L., \& Lee, C. M. 2014. Development and Behavioral Pattern Analysis of A Mobile Guide System with Augmented Reality for Painting Appreciation Instruction in an art Museum, Computers \& Education, 71(1): 185-197.

[4] Preece, J., Rodger, Y. \& Sharp, H. “Interaction Desain: Beyond Human-Computer Interaction”. John Wiley \& Sons, Inc.

[5] Cheng, K. H., \& Tsai, C. C 2014, Children and Parents' Reading of An Augmented Reality Picture Book: Analyses of Behavioral Patterns and Cognitive Attainment. Computers \& Education, 72(C):.https://doi.org/10.1016/j.compedu.2013.12.003

[6] Cai, S., Wang, X., \& Chiang, F. K 2014, A Case Study of Augmented Reality Simulation System Application in A Chemistry Course, Computers in Human Behavior, 37(37): 3140, https://doi.org/10.1016/j.chb.2014.04.018

[7] Falahah, Iwan Rijayana, Evaluasi Implementasi Sistem Informasi Dengan Pendekatan Utility System (Studi Kasus Sistem E-Campus Universitas Widyatama), Program Studi Teknik Universitas Widyatama, Fakultas Teknik, Universitas Widyatama Jurnal Ilmiah Kursor, Vol. 6, No. 2, Juli 2011 ISSN 0216 - 0544:1 
[8] Parlangeli, O., Marchigiani, E. \& Bagnara, S. "Multimedia System in Distance Education: Effects of Usability on Learning”, Journal of Interacting with Computer, Vol 12, Elsevier.

[9] Chen, X., Wu, H., Li, X., Luo, X., dan Qiu, T 2012, Real-time Visual Object Tracking via CamShift-Based Robust Framework, International Journal of Fuzzy Systems, Vol 14, June 2012, No 2.

[10] Rinci Kembang Hapsari, Nur Sulaiman, Luky Agus Hermanto 2016, Aplikasi FindgoITATS Berbasis Android Dengan Algoritma SURF Untuk Menampilkan Informasi Lokasi Di ITATS, Integer Journal, No 1, Vol 1.

[11] Escobedo, L., Tentori, M., Quintana, E., Favela, J., \& Garciarosas, D 2014, Using Augmented Reality to Help Children with Autism Stay Focused, IEEE Pervasive Computing, 13(1).https://doi.org/10.1109/MPRV.2014.19

[12] Wang, Z., Yang, F 2012, Object Tracking Algorithm Based on Camshift and Grey Prediction Model in Occlusions, The $2^{\text {nd }}$ International Conference on Computer Application and System Modeling. 